\title{
Flora da Bahia: Caricaceae
}

\author{
Ana Maria Giulietti ${ }^{1,2 *}$, Reyjane Patrícia de Oliveira ${ }^{1, a}$, Herlon Alcântara Santos ${ }^{1, b}$, Daniela Santos \\ Carneiro-Torres $^{1, c}$ e Carla Teixeira de Lima ${ }^{d}$
}

${ }^{1}$ Programa de Pós-graduação em Botânica, Departamento de Ciências Biológicas, Universidade Estadual de Feira de Santana, Bahia, Brasil.

${ }^{2}$ Instituto Tecnológico Vale de Desenvolvimento Sustentável, Belém, Pará, Brasil.

\begin{abstract}
Resumo - É apresentando o tratamento taxonômico de Caricaceae para o estado da Bahia, Brasil. São reconhecidas quatro espécies: Jacaratia corumbensis, J. heptaphylla, J. spinosa e Vasconcellea quercifolia. O tratamento inclui chave de identificação, descrições e comentários para os táxons, além de ilustrações e mapas de distribuição para as espécies na Bahia.

Palavras-chave adicionais: florística, Jacaratia, taxonomia, Vasconcellea.
\end{abstract}

\begin{abstract}
Flora of Bahia: Caricaceae) - This is the taxonomic treatment of the Caricaceae from Bahia state, Brazil. Four species are recognized: Jacaratia corumbensis, J. heptaphylla, J. spinosa and Vasconcellea quercifolia. The treatment includes an identification key, descriptions and general comments for the taxa, as well as illustrations and distribution maps of the species in Bahia.

Additional key words: floristics, Jacaratia, taxonomy, Vasconcellea.
\end{abstract}

\section{CARICACEAE}

Árvores, arbustos, ou raramente ervas, latescentes; látex branco ou amarelo-claro. Folhas alternas, simples, frequentemente lobadas, ou compostas, inteiras ou serreadas nas margens; estípulas presentes ou não, às vezes modificadas em espinhos. Inflorescências cimosas ou reduzidas a uma única flor. Flores vistosas, diclamídeas, pentâmeras, actinomorfas, prefloração valvar, imbricada ou convoluta, unissexuadas (geralmente em plantas dioicas, raramente em plantas polígamo-dioicas ou monoicas) ou raramente bissexuadas; sépalas 5, unidas, às vezes cálice muito reduzido; pétalas 5, unidas, formando um tubo longo nas flores estaminadas e um tubo curto a muito curto nas pistiladas; flores estaminadas com 10 estames epipétalos em 2 verticilos, anteras bitecas, tetrasporângiadas, rimosas, pistilódio geralmente presente; flores pistiladas com ovário súpero, 5-carpelar, 1- ou 5-locular, placentação parietal, raramente axilar. Frutos bagas.

Caricaceae inclui seis gêneros. Cylicomorpha Urb., com duas espécies, está restrito à África. Os demais são nativos das Américas, do México ao Paraguai: Jarilla Rusby, com três espécies de ervas perenes, ocorre no México e Guatemala; Horovitzia V.M.Badillo, com uma única espécie, H. cnidoscoloides (Lorence \& R. Torres) V.M.Badillo, está restrito ao sul do México; Carica L. é natural do sul do México e Guatemala e incluindo apenas $C$. papaya L., a espécie que produz o

\footnotetext{
*Autora para correspondência: anagiulietti@hotmail.com;

arpatricia@uefs.br; bherlon_alcantara@yahoo.com.br;

cdscarneiro@hotmail.com; dcarla.lima@itv.org

Editor responsável: Alessandro Rapini

Submetido: 3 maio 2018; aceito: 11 ago. 2018

Publicação eletrônica: 21 ago 2018; versão final: 24 ago. 2018
}

mamão ou papaya, fruta com grande importância econômica em nível mundial. Finalmente, Jacaratia A.DC. e Vasconcellea A.St-Hil. são os maiores gêneros da família, com seis e 20 espécies, respectivamente (Souza \& Lorenzi 2012; Carvalho 2013; Carvalho \& Renner 2013a). A família tem sido estudada recentemente sob várias abordagens, desde a caracterização das espécies e seu uso como modelo para e-taxonomia à biogeografia dos gêneros, origem e relacionamento de Carica papaya (Carvalho 2013; Carvalho \& Renner 2013a,b; Carvalho 2014; Carvalho et al. 2015). O BFG (2015) menciona nove espécies para o Brasil, sendo Jaracatia e Vasconcellea, com quatro espécies cada, nativos e Carica papaya naturalizada. Aqui, reconhecemos três espécies de Jacaratia e uma de Vasconcellea como nativas da Bahia. Carica papaya é amplamente cultivada no Estado e os 49 registros da espécie na Bahia incluídos no SpeciesLink parecem remeter a locais de cultivo, arredores de áreas cultivadas, sítios ou quintais. Ainda que indivíduos isolados eventualmente possam ser encontrados nos arredores de áreas habitadas, a espécie não parece estar naturalizada na Bahia. Assim, Carica papaya está incluída na chave de identificação como cultivada, mas não é tratada formalmente dentre as espécies da flora da Bahia.

\section{Chave para gêneros e espécies}

1. Folhas simples, lobadas ou denteadas; estames livres entre si.

2. Folhas peltadas, pecíolo com mais de $20 \mathrm{~cm}$ compr. (cultivada) .................... Carica papaya

2'. Folhas não peltadas, pecíolo com até $6,5 \mathrm{~cm}$ compr. .............. 2.1. Vasconcellea quercifolia

1'. Folhas compostas, digitadas; estames unidos entre si na base dos filetes 1. Jacaratia 
3. Arbustos a arvoretas, 1,3-2,5 m alt., sem acúleos; folhas com folíolo central de limbo inteiro ou lobado e folíolos laterais assimétricos na base 1.1. J. corumbensis

3'. Árvores, 4-20 m alt., com acúleos; folhas com folíolo central de limbo inteiro e folíolos laterais simétricos na base.

4. Folhas 3-folioladas; pedúnculo da inflorescência estaminada 0,4-1,6 cm compr.; cálice pubescente

\subsection{J. heptaphylla}

4'. Folhas 6-9-folioladas; pedúnculo da inflorescência estaminada 12,5-14 cm compr.; cálice glabro 1.3. J. spinosa

\section{Jacaratia A.DC.}

Árvores ou arbustos, dioicos; tronco pouco ramificado. Folhas compostas, digitadas; folíolos sésseis ou peciolulados. Flores em cimeiras axilares ou reduzidas a uma única flor, esverdeadas, brancas ou creme; cálice com prefloração imbricada; corola com prefloração imbricado-torcida; as estaminadas com 10 estames unidos na base dos filetes, os do verticilo externo maiores que os do verticilo interno, com pistilódio; as pistiladas com ovário 5-locular e 5 ramos estigmáticos lineares. Frutos ovoides ou elipsoides, lisos ou levemente 5-costelados, às vezes 5-lobados.

Jacaratia inclui duas espécies de áreas secas e quatro de florestas úmidas (Carvalho 2013). Para o Brasil, são referidas quatro espécies, distribuídas em todos os domínios fitogeográficos; três delas ocorrem na Bahia (BFG 2015).

1.1. Jacaratia corumbensis Kuntze, Rev. Gen. P1. 3: 101. 1898.

Figuras 1 e $2 \mathrm{~A}-\mathrm{H}$.

Nomes populares: chamburu, mamãozinho-de-veado e mamãozinho-do-mato.

Arbustos a arvoretas 1,3-2,5 m alt., cicatrizes foliares proeminentes, acúleos ausentes. Folhas digitadas, 3- ou 5-folioladas, caducas; pecíolo 6,6-9 cm compr.; folíolos pinatilobados, pinatipartidos ou ovais, membranáceos, glabros, discolores, adaxialmente verde-escuros, abaxialmente verde-claros, acuminados no ápice, inteiros ou irregularmente lobados nas margens, arredondados a truncados na base; o central 5,5-7 × 2,4-3 cm, com peciólulo 1,5-3,2 cm compr., simétrico na base; os laterais 5,5-7 × 2,4-3 cm, com peciólulo 1-3,2 cm compr., assimétricos na base. Flores estaminadas em fascículos; cálice ca. $1 \mathrm{~mm}$ compr.; corola 10,5-12,5 mm compr.; estames com filetes glabros, os do verticilo externo ca. $2,5 \mathrm{~mm}$ compr., os do interno ca. 1,6 mm compr.; pistilódio ca. $2 \mathrm{~mm}$ compr. Flores pistiladas solitárias; cálice ca. 1,2 $\mathrm{mm}$ compr.; corola ca. $10 \mathrm{~mm}$ compr.; ovário ca. 1,7 $\mathrm{mm}$ compr., estigmas ca. $3 \mathrm{~mm}$ compr. Bagas elipsoides, ca. $6 \times 2 \mathrm{~cm}, 5$-costeladas. Sementes ovoides, ca. $12 \times 9 \mathrm{~mm}$.
Distribuída do sudeste da Bolívia, passando pelo Brasil, até o norte da Argentina. No Brasil, ocorre nas Regiões Norte (Tocantins), Nordeste (Bahia, Ceará, Paraíba e Pernambuco), Centro-Oeste (Goiás e Mato Grosso do Sul) e Sudeste (Minas Gerais) (Flora do Brasil 2020, em construção), nos domínios da Caatinga, Cerrado e Pantanal (Badillo 1971). C6, C/D7, C8, D4, D6, D8, D9, E1/2, E5, E7, E8, F3, F4, F5, F6, G4 e G5: caatingas e cerrados, em ambientes áridos, com solos arenosos. Floresce de julho a setembro e frutifica de agosto a janeiro.

Material selecionado - Boquira, 1245'59'S, 42²4'06'W, 13 out. 2007 (fr.), A.A. Conceição et al. 2583 (HUEFS); Canudos, $10^{\circ} 01^{\prime}$ S, 3909'W, 20 set. 2003 (fl. §̊), F.H.M. Silva 442 (HUEFS);

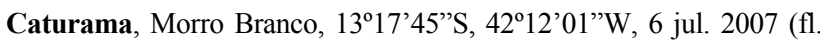
§), A.A. Conceição 2422 (HUEFS); Conceição do Coité, Serra do Mucambo, $11^{\circ} 30^{\prime}$ 'S, $39^{\circ} 12^{\prime} \mathrm{W}, 21$ out. 2012 (fl. Љ̊), D.N. Carvalho \& C. Takeuchi 116 (HUEFS); Contendas do Sincorá, 1345'46”'S, 4102'28”'W, 2 ago. 2017 (fl. đ)), G. Costa et al. 2654 (HURB);

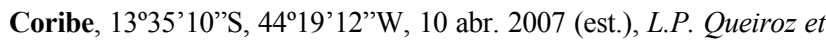
al. 12726 (HUEFS); Iaçu, 1247'57’S, 4008'23”'W, 25 ago. 2001 (fr.), A.C.S. Rocha \& B.S. Andrade 11 (HUEFS); Ibicoara, Morro

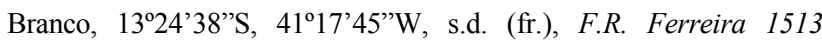

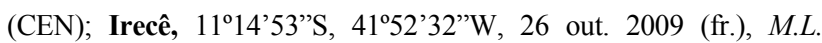
Guedes et al. 16165 (HUEFS); Itaberaba, 28 abr 1994 (bot.), L.P. Queiroz et al. 3891 (HUEFS); Itaetê, 11'59'11'S, 4058'21'W, 13 nov. 2014 (fr.), M.L. Guedes et al. 23082 (ALCB); Itatim, Morro das Tocas, 1242'43”S, 3941'53”'W, 22 dez. 2010 (fr.), E. Melo et al. 8966 (HUEFS); Ituaçu, 26 out. 20 (fr.), L.P. Queiroz et al. 14907

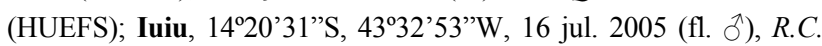
Forzza et al. 4064 (HUEFS); Jequié, 1351'04"S, 4004'52"W, 24 out. 2001 (fr.), W.W. Thomas et al. 12572 (CEPEC); João Dourado, $11^{\circ} 21^{\prime} \mathrm{S}, 41^{\circ} 35^{\prime} \mathrm{W}, 25$ jun. 2005 (fl. §ै), D.S. Carneiro-Torres et al. 532 (HUEFS); Jussiape, 1326'44”S, 41³3'19”'W, 10 ago. 2013 (fl.

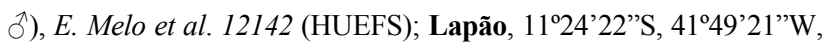
27 out. 2009 (fr.), E. Melo et al. 6899 (HUEFS); Licínio de Almeida, 14'40'56”'S, 42³0'27'W, 11 dez. 2009 (fr.), F.S. Gomes et al. 347 (ALCB, HUEFS); Milagres, 13 out. 2012 (fl. đ̊), E. Melo et al. 11576 (HUEFS); Monte Santo, 10²6'S, 39¹9'W, 12 jan. 2006 (fr.), M.L. Guedes et al. 12153 (ALCB); Morro do Chapéu, $20 \mathrm{~km}$ da estrada

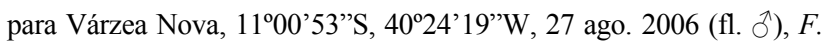
França et al. 5546 (HUEFS); Palmeiras, 12³1'44”S, 41'33'32”'W, 14 jul. 2012 (est.), J. Lombardi 9441 (HRCB); Morporá, 11²4'S, 43ํㄴ'W, 16 dez. 2007 (est.), A.A. Conceição et al. 2696 (HUEFS); Pituaçu, 1351'36”'S, 4117'20”'W, 9 ago. 1979 (bot.), J.E.M. Brazão

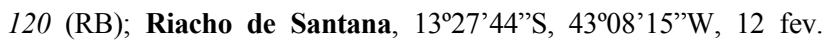
2000 (est.), L.P. Queiroz et al. 5941 (HUEFS); Rio de Contas, 13'34'44”'S, 4148'41'W, 18 jul. 2012 (fl. ㅇ), J. Lombardi 9589 (HRCB); São Desidério, 12²2’36”S, 455'08”W, 21 out. 2010 (fr.),

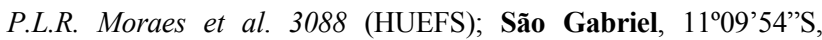
41'56’34”'W, 25 out. 2009 (fr.), E. Melo et al. 6942 (HUEFS); Tucano, $11^{\circ} 07^{\prime} 22^{\prime \prime}$, $38^{\circ} 46^{\prime} 23^{\prime \prime} \mathrm{W}, 7$ out. 2008 (fl. + +), D. Cardoso et

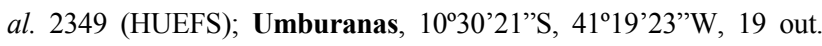
2008 (fr.), E. Melo et al. 5967 (HUEFS); Urandi, 14\%45'55”S, 42³9’03”W, 4 ago. 2009 (fl. §̊), M.L. Guedes et al. 15769 (HUEFS).

$\mathrm{Na}$ região semiárida nordestina, Jacaratia corumbensis tem importância econômica. Seus frutos servem de alimento para a fauna, o xilopódio de plantas 
jovens é utilizado para alimentação do gado na época de estiagem (Cavalcanti et al. 1999) e o látex produz enzimas coagulantes para o leite (Duarte et al. 2009).

\subsection{Jacaratia heptaphylla (Vell.) A.DC., Prodr. 15 (1):} 420. 1864.

Figuras 1 e 2I-O.

Nomes populares: jacatiá-mirim, mamãozinho.

Árvores 4-8,5 $\mathrm{m}$ alt., cicatrizes foliares proeminentes, acúleos presentes. Folhas digitadas, 3folioladas, não caducas; pecíolo 5,5-13 cm compr.; folíolos elípticos a lanceolados, cartáceos, glabros, discolores, adaxialmente verde-escuros e amarronzados, abaxialmente verde-claros, acuminados no ápice, inteiros nas margens, arredondados na base; o central 9,5-13 × 3,2-4,5 cm, com peciólulo $0,4-1 \mathrm{~cm}$ compr., simétrico na base; os laterais 7-9,5 × 3,3-4,5 $\mathrm{cm}$, com peciólulo 0,4-1 $\mathrm{cm}$ compr., simétricos na base. Flores estaminadas em racemos com pedúnculo 0,4-0,6 mm compr.; cálice ca. $1 \mathrm{~mm}$ compr., pubescente; corola 10-12 mm compr.; estames com filetes pubescentes, os do verticilo externo ca. $2,1 \mathrm{~mm}$ compr., os do interno ca. 1,8 mm compr.; pistilódio ca. $1 \mathrm{~mm}$ compr. Flores pistiladas solitárias, não vistas. Bagas elipsoides, 4-6 6 1,2-2,5 cm, com 5 costelas salientes. Sementes ovoides, ca. $9 \times 6 \mathrm{~mm}$.

Jacaratia heptaphylla é endêmica do Brasil, ocorrendo principalmente no domínio da Mata Atlântica (Badillo 1971). Está distribuída no Nordeste (Bahia), Sudeste (Espírito Santo, Minas Gerais, Rio de Janeiro e São Paulo) e Centro-Oeste (Mato Grosso do Sul) (Flora do Brasil 2020, em construção). D9, E9/10, F5, F8, G7, G8, H8, H8/9, I8/9 e J8: Mata Atlântica, especialmente em restingas e matas mesófilas. Floresce de junho a outubro e frutifica de maio a julho.

Material selecionado - Alcobaça, $17^{\circ} 31^{\prime} 10^{\prime \prime} \mathrm{S}, 39^{\circ} 11^{\prime} 44^{\prime \prime} \mathrm{W}$, 16 set. 1978 (fr.), T.S. Santos et al. 3314 (CEPEC); Almadina, $14^{\circ} 42^{\prime} 19^{\prime \prime}$ S, 39³8'14”'W, s.d., (fl. ô), J.G. Jardim 1406 (CEPEC); Amargosa, $13^{\circ} 10^{\prime}$ 'S, $39^{\circ} 09^{\prime} \mathrm{W}, 28$ abr. 2007 (fr.), J.L. Paixão et al.

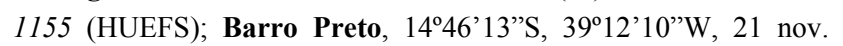
2005 (fl. O) $^{\text {) }, ~ M . M . M . ~ L o p e s ~ e t ~ a l . ~} 350$ (CEPEC); Boa Nova, $14^{\circ} 21^{\prime} 45^{\prime}$ 'S, $40^{\circ} 12^{\prime} 27^{\prime}$ 'W, 14 ago. 2013 (fl. $\left.0^{\Uparrow}\right)$, D.C. Zappi \& J.G.

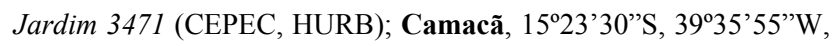
5 jun. 2006 (fr.), M.M.M. Lopes \& Lopes 781 (CEPEC); Canavieiras, 22 jul. 1981 (est.), L.A. Mattos-Silva et al. 1335

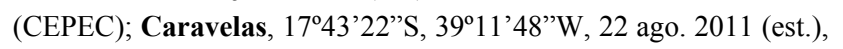
E. Matos et al. 2488 (HUEFS); Caturama, 1317'45”S,

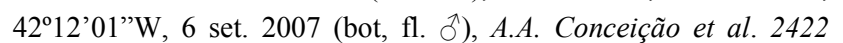
(HUEFS); Entre Rios, $12^{\circ} 10^{\prime} \mathrm{S}, 37^{\circ} 58^{\prime} \mathrm{W}, 25$ fev. 2015 (fr.), A.V. Popovkin \& J.C. Mendes 1877 (HUEFS); Ilhéus, Serra Grande, 22 out. 1983 (bot., fl. ठ), A.M. Carvalho et al. 2003 (CEPEC, RB); Itacaré, $14^{\circ} 16^{\prime} 39^{\prime \prime} \mathrm{S}, 38^{\circ} 59^{\prime} 48^{\prime \prime} \mathrm{W}, 5$ out. 2012, (est.) N.A. Sousa 8

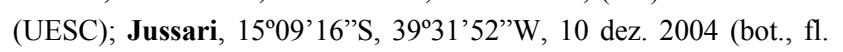

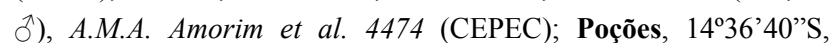
4020'13”'W, 7 fev. 2004 (fr.), W.W. Thomas et al. 13914 (CEPEC); Porto Seguro, 16 $26^{\prime} 59^{\prime}$ 's, 39³'53”W, 6 abr. 1994 (fr.), A.M. Carvalho et al. 4478 (CEPEC); Santa Cruz Cabrália, 17 jan. 1984

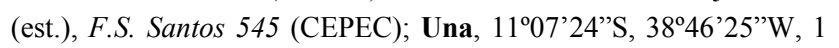
maio 1996 (fr.), J. Jardim et al. 810 (HUEFS); Uruçuca,
14³5'35"S, 39¹7’04”W, 20 abr. 2000, (fr.) J.G. Jardim 2960 (CEPEC).

$\mathrm{Na}$ Bahia, a espécie se distingue por ser uma árvore da Mata Atlântica com folhas 3-folioladas, além dos frutos com costelas salientes (Badillo 1971). É considerada importante na sucessão ecológica da Mata Atlântica, sendo pioneira na ocupação de clareiras (Samir et al. 1999).

1.3. Jacaratia spinosa (Aubl.) A.DC., Prodr. 15(1): 419. 1864.

Figuras 3 e 4 A-G.

Nomes populares: mamão-bravo e mamão-do-mato.

Árvores $12-20 \mathrm{~m}$ alt., cicatrizes foliares proeminentes, acúleos presentes. Folhas digitadas, $6-$ 9-folioladas, não caducas; pecíolos $12,5-15,7(-35) \mathrm{cm}$ compr.; folíolos oblanceolados a elípticos, papiráceos, glabros, fortemente discolores, adaxialmente verdeescuros, abaxialmente verde-esbranquiçados, cuspidados no ápice, inteiros nas margens, agudos na base; o central 10-14,2 × 2,6-4,5 cm, com peciólulo $0,3-0,4 \mathrm{~cm}$ compr., simétrico na base; os laterais 10 $14,2 \times 2,6-4,1 \mathrm{~cm}$, com peciólulo $0,3-0,4 \mathrm{~cm}$ compr., simétricos na base. Flores estaminadas em panículas com pedúnculo 10,5-14 cm compr.; cálice 1,2-1,3 mm compr., glabro; corola 15,3-16 mm compr.; estames com filetes pubescentes, os do verticilo externo 3-4 $\mathrm{mm}$ compr., os do interno ca. $1,2 \mathrm{~mm}$ compr.; pistilódio ca. $1,5 \mathrm{~mm}$ compr. Flores pistiladas solitárias, não vistas. Bagas elipsoides ou ovoides, 7,5$9 \times 4-5 \mathrm{~cm}$, sem costelas. Sementes ovoides, ca. $5 \times 3$ $\mathrm{mm}$.

Distribuída da Nicarágua ao norte da Argentina, em áreas tropicais úmidas ou sazonais com estação seca prolongada, ocorrendo desde o nível do mar até a

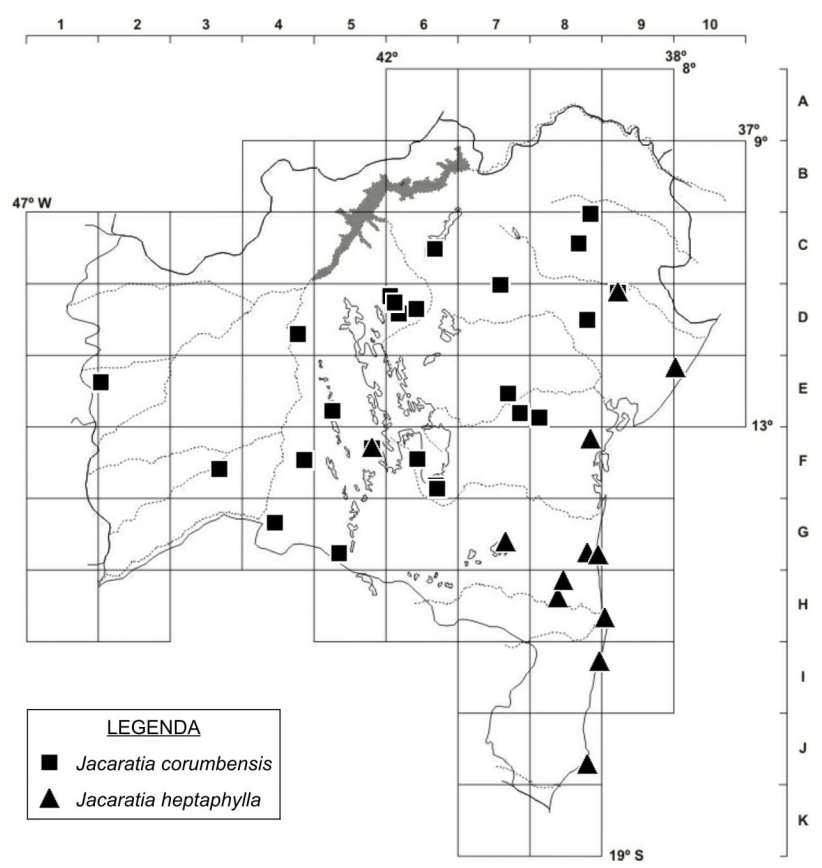

Figura 1. Mapa de distribuição de Jacaratia corumbensis e $J$. heptaphylla no estado da Bahia. 


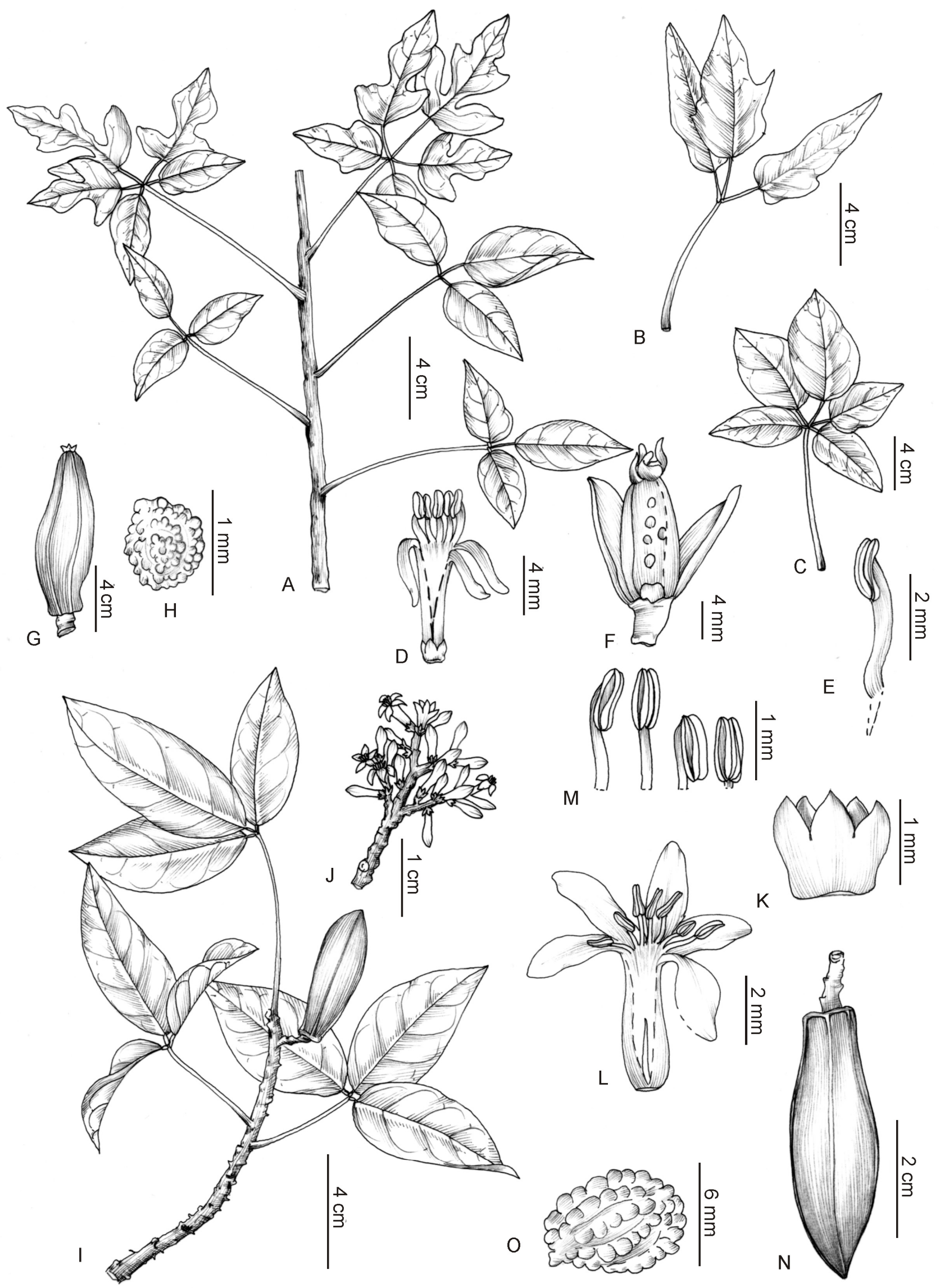

Figura 2. A-H. Jacaratia corumbensis: A- ramo; B- folha trifoliolada; C- folha pentafoliolada (Queiroz 3891); D- flor estaminada, corte longitudinal; E- estame; F- flor pistilada (França 5546); G- fruto; H- semente (Rocha 11). I-O. J. heptaphylla: I- ramo com fruto; J- inflorescência; K- cálice; L- flor estaminada, corte longitudinal; M- estames (Lopes 350); N- fruto; O- semente (Jardim 810). 
altitude de $1300 \mathrm{~m}$ (Badillo 1971). No Brasil, é encontrada especialmente na Mata Atlântica, do Nordeste até o Sul, mas também ocorre na floresta amazônica (Lorenzi 2002; Flora do Brasil 2020, em construção). E7, E8, E9/10, G8 e H8: Mata Atlântica, em matas ombrófilas e mesófilas. Floresce de setembro a outubro e frutifica de outubro a janeiro.

Material selecionado - Anguera, fazenda Retiro, 12 $09^{\prime} 42^{\prime \prime} \mathrm{S}$, $39^{\circ} 11^{\prime} 02^{\prime}$ 'W, 25 maio 2007 (est.), D. Cardoso et al. 1949 (HUEFS); Camacã, 27 nov. 1968 (bot.), J. Almeida et al. 243 (CEPEC, RB); Esplanada, 120'00”S, 37 $58^{\circ} 12^{\prime \prime} \mathrm{W}, 28$ mar. 2013 (est.), A.V. Popovikin \& J.C. Mendes 1395 (HUEFS); Ilhéus, 18 nov. 1981, (bot., fl. §), J.L. Hage 1525 (ALCB, CEPEC, HUEFS, RB); Itaberaba, fazenda Leão dos Brejos, $12^{\circ} 24^{\prime} 45^{\prime \prime} \mathrm{S}, 40^{\circ} 31^{\prime} 36^{\prime} \mathrm{W}, 14$ mar. 2012, (est.), L.P. Queiroz 15383 (HUEFS); Itabuna, 1447'8'S, 39¹6'49'W, 8 mar. 1978, (fr.), S.A. Mori et al. 9558 (CEPEC); Jussari, 15¹1'29”S, 39²9'43”W, 9 fev. 1998, (fl.), W.W. Thomas et al. 11761 (CEPEC).

$\mathrm{Na}$ Bahia, Jacaratia spinosa está restrita à Mata Atlântica. Em Linhares (Espírito Santo), é uma espécie secundária inicial (Samir et al. 1999). O fruto serve de alimento para pássaros e outros animais silvestres, e assemelha-se ao de Carica papaya (mamoeiro) pela cor e textura, mas são menores (Lorenzi et al. 2006). Os frutos dessas duas espécies possuem propriedades medicinais semelhantes, sendo usados como antihelmíntico e anti-inflamatório (Lorenzi \& Mattos 2002).

\section{Vasconcellea A.St.-Hil.}

Arbustos ou árvores; tronco simples ou pouco ramificado. Folhas simples. Flores em cimeiras ou racemos axilares, esverdeadas, brancas a creme; cálice com prefloração imbricada; corola com prefloração imbricado-torcida; as estaminadas com estames livres entre si, os do verticilo externo maiores que os do verticilo interno, com pistilódio; as pistiladas com ovário 5-locular e 5 ramos estigmáticos lineares. Frutos ovoides ou elipsoides, lisos ou levemente 5costelados, às vezes 5-lobados.

Vasconcellea inclui 20 espécies, com distribuição neotropical e centro de diversidade nos Andes (Carvalho 2013; Carvalho \& Renner 2013b). Era tratada como seção de Carica s.l., tendo sido restabelecido por Badillo (2000), ficando Carica com apenas uma espécie. São referidas quatro espécies para o Brasil, distribuídas em todos os domínios fitogeográficos, das quais apenas uma está representada na Bahia (Flora do Brasil 2020, em construção).

\subsection{Vasconcellea quercifolia A.St.-Hil., Deux. Mém.} Réséd.: 13.1837.

Figuras 3 e 4 H-N.

Nome popular: mamãozinho-de-mato.

Arbustos a arvoretas 1,2-4 $\mathrm{m}$ alt., cicatrizes foliares proeminentes, acúleos ausentes. Folhas simples, caducas; pecíolo 1,2-6,5 cm compr.; limbo lobado 6-21 × 2,4-14 cm, cartáceo, glabro, discolor, adaxialmente verde-escuro, abaxialmente verde-claro, obtuso a agudo no ápice, inteiro ou lobado nas margens, arredondado a truncado e assimétrico na base. Flores estaminadas em panículas com pedúnculo 4 $8,5 \mathrm{~cm}$ compr.; cálice ca. $1 \mathrm{~mm}$ compr., glabro; corola 9-10,5 mm compr.; estames com filetes pubescentes, os do verticilo externo ca. $2 \mathrm{~mm}$ compr., os do interno ca. 0,5 mm compr.; pistilódio ca. 6,2 $\mathrm{mm}$ compr. Flores pistiladas em racemos de poucas flores; cálice ca. 1,2 mm compr.; corola ca. $15 \mathrm{~mm}$ compr.; ovário ca. $7 \mathrm{~mm}$ compr., estigmas ca. $3 \mathrm{~mm}$ compr. Bagas elipsoides, imaturas ca. 2,2 × $0,9 \mathrm{~cm}, 5$-costeladas. Sementes ovoides, ca. $6 \times 4 \mathrm{~mm}$.

Ocorre na Argentina, Bolívia, Brasil, Paraguai, sul do Peru e Uruguai (Badillo 1993). No Brasil, está distribuída no Nordeste (Bahia, Ceará e Sergipe), Sudeste (Espírito Santo, Rio de Janeiro e São Paulo), Centro-Oeste (Goiás, Mato Grosso e Mato Grosso do Sul) e Sul (Paraná, Rio Grande do Sul e Santa Catarina) nos domínios da Caatinga, Cerrado, Mata Atlântica e Pampa (Flora do Brasil 2020, em construção). D6: caatingas. Coletada com flores e frutos de setembro a novembro.

Material selecionado - Irecê, margem da estrada para Angical, 8 out. 1980 (fr.), E.L.P. Oliveira 194 (BHA); Itaberaba, 12³1'39”'S, 40¹8'25”W s.d. (fr.), F.R. Ferreira 1495 (CEN); Itiúba, 1041'30”'S, 3951'13”'W, 26 maio 1983 (fl. đ̋), G.C.P. Pinto et al. 88/83 (ALCB);

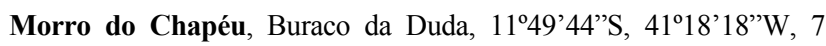
nov. 2008 (fl. §̊), E. Melo et al. 6046 (HUEFS).

Material adicional: Botucatu, São Paulo, 24 dez. 2011 (fl. ㅇ) ), L. Biral \& D.G. Gomes 650 (HUEFS).

Vasconcellea quercifolia é rara na Bahia, com apenas cinco registros nos herbários examinados. É facilmente reconhecida entre as espécies de Caricaceae do Estado pelas folhas simples. No semiárido, o sistema subterrâneo desenvolvido da planta jovem é utilizado na fabricação de doce (Oliveira 194, in sched.).

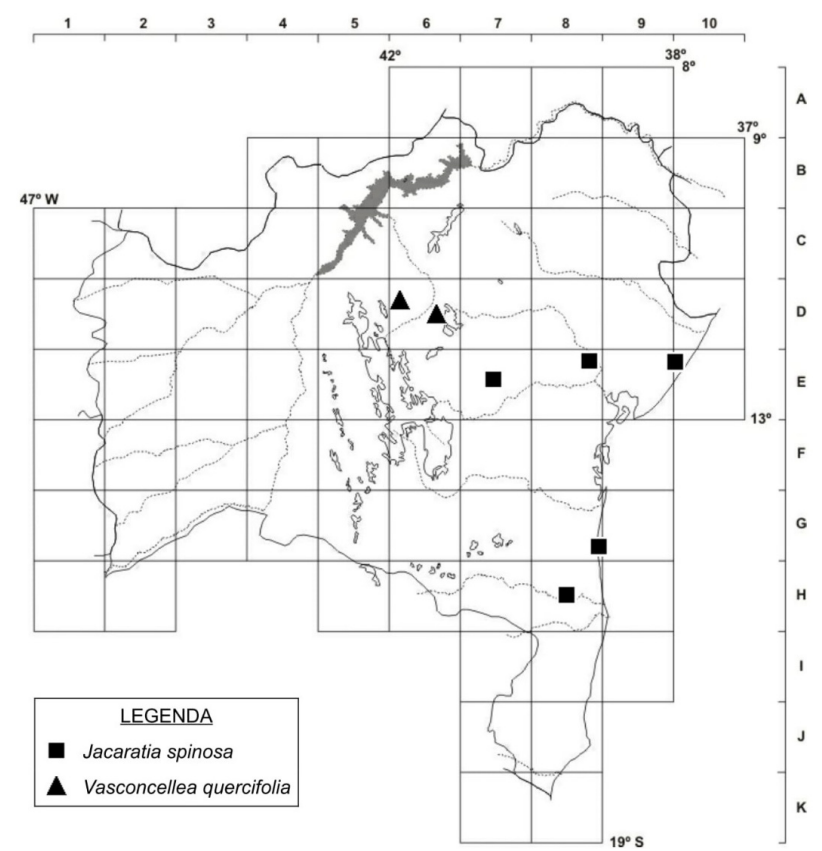

Figura 3. Mapa de distribuição de Jacaratia spinosa e Vasconcellea quercifolia no estado da Bahia. 


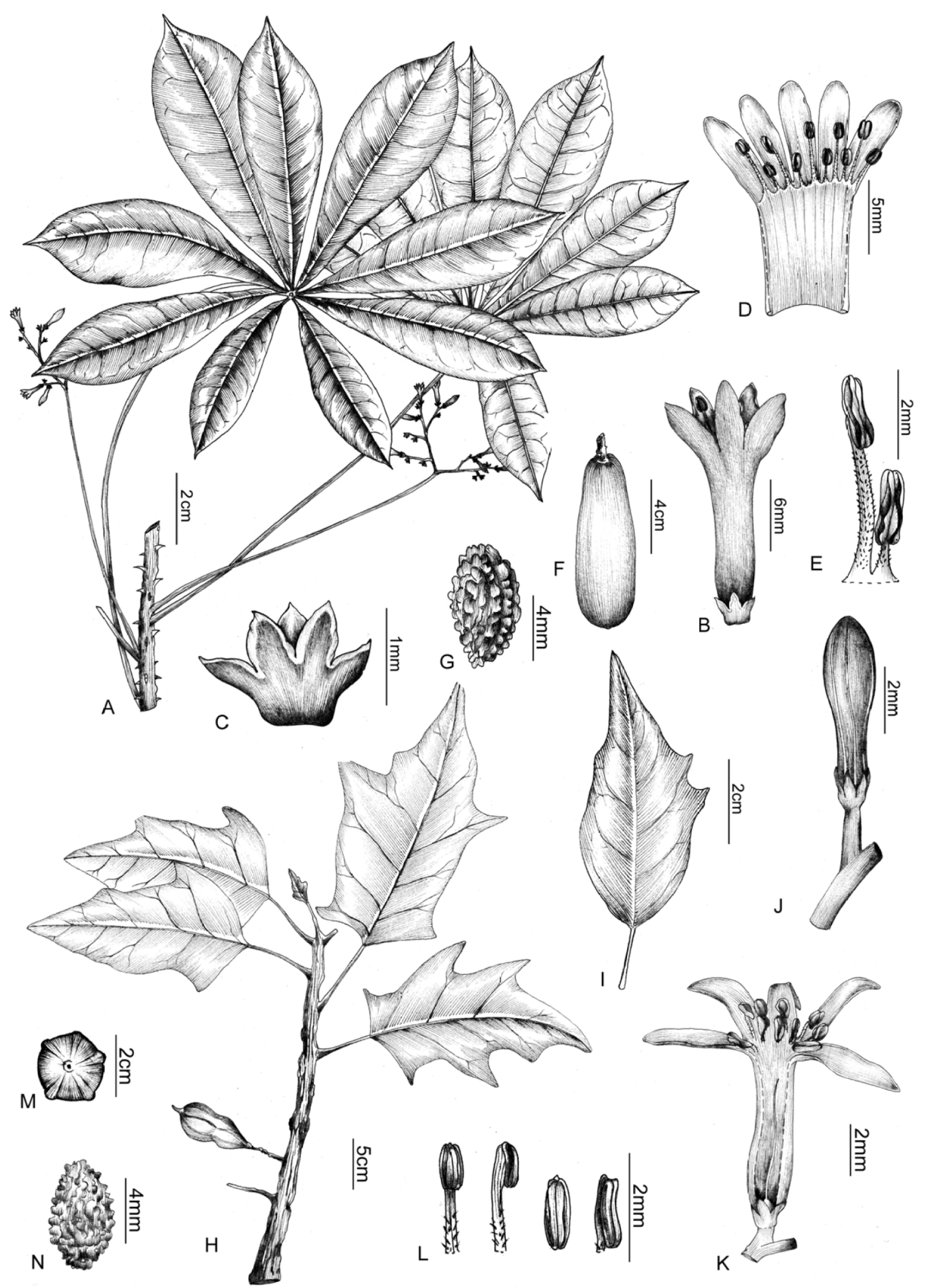

Figura 4. A-G. Jacaratia spinosa: A- ramo florido (folhas de Cardoso 1949; inflorescências de Hage 1525); B- flor estaminada; C- cálice; D- flor estaminada, corte longitudinal; E- estames (Hage 1525); F- fruto; G- semente (Amorim 9558). H-N. Vasconcellea quercifolia: H- ramo com fruto; I- folha inteira (Damascena 150); J- botão floral; K- flor estaminada, corte longitudinal; L- estames (Melo 6040); M- fruto; N- semente (Biral 650). 


\section{AGRADECIMENTOS}

Aos curadores dos herbários ALCB, ASE, CEPEC, HRB e HUEFS, pelo acesso às coleções; ao CNPq e à FAPESB, pelo financiamento dos projetos Flora da Bahia FAPESB APR 162/2007, CNPq Proc. 562278/2010-9 e 483909/2012, e ao CNPq/Projeto PPBio do Semiárido, pelo auxílio na realização de visitas aos herbários e expedições de campo; à CAPES, pela bolsa de doutorado de CTL; ao Leandro Soares Pereira Lima, pela edição das pranchas. AMG e RPO agradecem ao CNPq pela bolsa de Produtividade em Pesquisa.

\section{REFERÊNCIAS}

Badillo, V.M. 1971. Monografia de la família Caricaceae. Universidad Central de Venezuela, Facultad de Agronomia, La Asociacion de Professores, Maracay.

Badillo, V.M. 1993. Caricaceae, segundo esquema. Revista de la Facultad de Agronomia de la Universidad Central de Venezuela. Alcance 43: 1-111.

Badillo, V.M. 2000. Carica L. vs. Vasconcella St. Hil. (Caricaceae) com la rehabilitación de este último. Ernstia 10(2): 74-79.

BFG (The Brazil Flora Group) 2015. Growing knowledge: an overview of Seed Plant diversity in Brazil. Rodriguésia 66(4): 1085-1113.

Carvalho, F.A. 2013 onwards. E-Monograph of Caricaceae. Version 1, November 2013 [Database continuously updated]. Disponível em: http://herbaria.plants.ox.ac.uk/bol/caricaceae. Acesso em: maio 2016.

Carvalho, F.A. 2014. Molecular Phylogeny, Biogeography and an E-Monograph of the Papaya Family (Caricaceae) as an Example of Taxonomy in the Electronic Age. Dissertation Ludwig-Maximilians-Universität München, Springer Spectrum, München.
Carvalho, F.A. \& Renner, S.S. 2013a. Correct names for some of the closest relatives of Carica papaya: a review of the Mexican/Guatemalan genera Jarilla and Horovitzia. PhytoKeys 29: 63-74.

Carvalho, F.A. \& Renner, S.S. 2013b. The phylogeny of the Caricaceae. In: R. Ming \& P.H. Moore (eds), Genetics and Genomic of Papaya. Springer, Heidelberg, p. 81-92.

Carvalho, F.A.; Files, D. \& Renner, S.S. 2015. Taxonomy in the electronic age and an e-monograph of the papaya family (Caricaceae) as an example. Cladistics 31: 321-329.

Cavalcanti, N.B.; Lima, J.L.S.; Resende, G.M. \& Brito, L.T.L. 1999. Estudo do xilopódio do mamãozinho-de-veado (Jacaratia corumbensis O. Kuntze) no semi-árido do Nordeste. $50^{\circ}$ Congresso Nacional de Botânica. SBB, Blumenau.

Duarte, A.R.; Rodrigues, D.M.R.; Moreira, K.A.; Cavalcanti, M.T.H; Lima-Filho, J.L. \& Porto, A.L.F. 2009. Jacaratia corumbensis O. Kuntze, a new vegetable source for milkclotting enzymes. Brazilian Archives of Biology and Technology 52(1). Doi.10.1590/S1516-89132009000100001.

Flora do Brasil 2020, em construção. Jardim Botânico do Rio de Janeiro. Disponível em: < http://floradobrasil.jbrj.gov.br/ >. Acesso em: 3 maio 2018.

Lorenzi, H. 2002. Caricaceae. In: Arvores Brasileiras: manual de identificação e cultivo de plantas arbóreas do Brasil. Vol. 1. $4^{\circ}$ ed. Editora Platarum, Nova Odessa, p. 93.

Lorenzi, H. \& Mattos, F.J.A. 2002. Caricaceae. In: Plantas Medicinais no Brasil - nativas e exóticas. Instituto Plantarum, Nova Odessa, p. 115-116.

Lorenzi, H.; Bacher, L.; Lacerda, M. \& Sartori, S. 2006. Caricaceae. In: Frutas Brasileiras e Exóticas Cultivadas. Instituto Plantarum, Nova Odessa, p. 108-109.

Samir, G.R.; Zarate, H.T.C. \& Moraes, R.J. 1999. Mortalidade e recrutamento de árvores na Floresta Atlântica em Linhares, Espírito Santo. Scientia Florestalis 55: 49-69.

Souza, V.C. \& Lorenzzi, H. 2012. Caricaceae. In: Botânica Sistemática. Guia ilustrado para identificação das famílias de angiospermas da flora brasileira, baseado em APG II. Instituto Plantarum, Nova Odessa, p. 402.

\section{LISTA DE EXSICATAS}

Almeida, J. 243 (1.3); Amorim, A.M. 1607, 4474, 7230 (1.2); Aona, L.Y.S. 3017 (1.2); Bautista, H.P. PCD 4533 (1.1); Biral, L. 650 (2.1); Brazão, J.E.M. 120 (1.1); Cardoso, D. B. 884, 910, 1831 (1.1), 1949 (1.3), 2349, 2693, 2695 (1.1); Carneiro-Torres, D.S. 532 (1.1); Carvalho, A.M. 2003, 4478, 4722, 5237 (1.2); Carvalho, D.N. 581; 116 (1.1); Cavalcanti, A.C.S. 28 (1.2); Conceição, A.A. 2422 (1.2), 2583, 2696 (1.1); Costa, G. 2654 (1.1); Damascena, L. 150 (2.1); Ferreira, F.R. 1493 (1.1), 1495 (2.1), 1496 (1.2), 1497, 1500 (1.1), 1503, 1504 (1.2), 1506 (1.3), 1511, 1513, 1514, 1515 (1.1); França, F. 5546 (1.1); Forzza, R.C. 4064 (1.1); Gomes, F.S. 347 (1.1); Guedes, M. L. 12153, 15769, 16165, 23082 (1.1); Hage, J.L. 1525 (1.3); Hummel, M. 88 (1.3); Jardim, J.G. 810, 2960 (1.2); Lombardi, J., 9441 , 9589 (1.1); Lopes, M.M.M. 220, 350, 781 (1.2); Machado, R.F. 564 (1.1); Matos, E. 2488, 3403 (1.2); Mattos-Silva L.A. 1335, 2963, 3876, 4645 (1.2); Melo, E. 5967 (1.1), 6046 (2.1), 6899, 6942, 8966, 11576, 12142 (1.1); Miranda, A.M. 5521 (1.1); Moraes, P.L.R. 3088 (1.1); Mori, S.A. 9558 (1.3), 13973 (1.2); Oliveira, E.L.P.G. 194, 271 (2.1); Paixão, J.L. 1155 (1.2); Pinto, G.C.P. 52/84 (1.1), 88/83 (2.1); Popovink, A.V. 1395 (1.3), 1877 (1.2); Queiroz, L.P 3891, 5941, 12726, 13667, 13668, 14907 (1.1); 15383 (1.3); Rocha, A.C.S. 11 (1.1); Santos, F.S. 111, 545 (1.2); Santos, R.M. 1756 (1.1); Santos T.S. 2838 (1.3), 3273, 3324 (1.2); Silva, F.H.M. 442 , 477 (1.1); Sousa, N.A. 8 (1.2); Thomas, W.W. 6881 (1.2), 11761 (1.3), 12572 (1.1), 13914 (1.2); Zappi, D.C. 3471 (1.2). 